\title{
Normatividad y buenas prácticas: por una cultura archivística en el Departamento de Investigaciones Educativas del Centro de Investigaciones y Estudios Avanzados (Cinvestav)
}

Regulations and best practices: for an archival culture in the Department of Educational Research at the Center for Research and Advanced Studies (Cinvestav)

\author{
María Elena Maruri Carrillo \\ Departamento de Investigaciones Educativas \\ Centro de Investigaciones y Estudios Avanzados (Cinvestav) \\ emaruri@Cinvestav.mx
}

Día de la premiación: 8 de octubre de 2015

\section{Resumen}

Hoy día, ante las nuevas disposiciones oficiales en materia de archivos para las dependencias y entidades del país, surge la obligación de atender la organización de los archivos del Centro de Investigaciones y Estudios Avanzados (Cinvestav), lo que torna ser un reto den tro de las actividades cotidianas de la institución; empezando por cambiar las formas tradicionales de manejar la información hasta aplicar adecuadamente los lineamientos que han emitido tanto el Instituto Nacional de Transparencia, Acceso a la Información y Protección de Datos Personales (INAI) como el Archivo General de la Nación (AGN) al respecto. Particularmente, en el Departamento de Investigaciones Educativas (DIE) se tiene la propuesta de modernizar la organización y clasificación de sus archivos (de trámite, de concentración e histórico) en cumplimiento con la normatividad correspondiente.

Palabras clave: normatividad, cultura archivística, leyes, archivos, organización documental, Cinvestav

\section{Abstract}

Today, in the face of new official regulations regarding archival preservation for the government agencies and entities of the country, the obligation to attend the organization of the archives of the Centre for Research and Advanced Studies (Cinvestav) arises, which makes meeting this challenge one of the daily activities of the institution; from beginning to change traditional ways of managing information to properly implementing the relevant guidelines issued by both the National Institute of Transparency, Access to Information and Protection of Personal Data (INAI) and the General Archive of the Nation (AGN). In particular, in the Department of Educational Research (DIE) there is a proposal to modernize the organization and classification of their archives (current, concentration and historical) in compliance with the appropriate regulations.

Keywords: Historiographical and documentary research, History of teaching, Education History 
A partir de la expedición de las normas jurídicas en materia de Transparencia y Acceso a la Información (2002) por el Poder Ejecutivo, el Instituto Federal de Acceso a la Información Pública (IFAI), hoy Instituto Nacional de Transparencia, Acceso a la Información y Protección de Datos Personales (INAI), ha emitido los estatutos correspondientes para regular la transparencia en la información reservada y confidencial en la Administración Pública Federal (APF), mediante la Ley Federal de Transparencia y Acceso a la Información Pública Gubernamental (LFTAIPG).

Ante esta medida precautoria, las dependencias y entidades de la APF, como es el caso del Centro de Investigaciones y de Estudios Avanzados (Cinvestav), se convierten en sujetos obligados, es decir, que la institución debe apegarse a esta ley, acatando lo expuesto en su artículo 1: "garantizar el acceso de toda persona a la información en posesión de los Poderes de la Unión, los Órganos Constitucionales Autónomos o con autonomía legal..."1 así como respetar la Ley Orgánica de la Administración Pública Federal (LO-APF).

El acceso a la información depende de los archivos institucionales en tanto que concentran la información fidedigna. Los archivos, como parte del patrimonio propio de los órganos públicos, son "medio e instrumento de las acciones de gobierno y parte medular del conocimiento de las instituciones gubernamentales". ${ }^{2}$ Por ello deben ser organizados correctamente para posibilitar su acceso a la información y facilitar la rendición de cuentas y la transparencia de gestión. ${ }^{3}$

\footnotetext{
${ }^{1}$ El Artículo décimo transitorio de la LFTAIPG instaura que los sujetos obligados deberán, a más tardar el 1 de enero de 2005, tener funcionando de forma organizada sus archivos, así como la publicación de la guía a que se refiere el artículo 32 de la misma ley ("Lineamientos Generales de la Organización y Conservación de los Archivos de las Dependencias y Entidades de la Administración Pública Federal", en adelante "Lineamientos Generales").

${ }^{2}$ Barnard Amozorrutia, Guía para la organización, p. 7.

3 "Ley Federal de Archivos" (en adelante LFA), 2012; Artículo 6, fraccs. IV-V.
} 
Bajo este contexto y en cumplimiento con las obligaciones administrativas, la Ley Federal de Archivos (LFA) y su Reglamento ${ }^{4}$ han tenido a bien emitir el marco legal correspondiente para que las dependencias y entidades ${ }^{5}$ del Poder Ejecutivo organicen, clasifiquen y cataloguen sus archivos de trámite, de concentración e histórico para:

...asegurar la disponibilidad, localización expedita, integridad y conservación de los documentos de archivo que poseen los sujetos obligados; $;^{6}$ dado que los archivos constituyen la memoria de la actuación de la Administración Pública; son el testimonio de los derechos y obligaciones de los ciudadanos y de la propia administración. Son factor imprescindible de continuidad en los cambios de las estructuras administrativas y de los funcionarios. ${ }^{7}$

Las prácticas de ordenamiento en los archivos, como el resguardo y custodia, así como el proceso de clasificación y valoración, se norman mediante un marco jurídico que reconoce la necesidad de conservar la trayectoria institucional de la administración pública. Así, la cultura de la archivística se convierte en eje de la actividad gubernamental que debe ser promovida por los funcionarios encargados de preservar y fomentar el valor de los archivos como bien patrimonial de las instituciones. ${ }^{8}$

Los esfuerzos de los archivistas y el equipo especializado en materia de archivos, como el Comité Técnico Consultivo de Unidades de Correspondencia y Archivo (Cotecuca), hoy Comité Técnico Interno de Administración de Documentos (COTECiAD) y el Sistema Nacional

${ }^{4}$ En el reglamento de la LFA, 2014, se fundamenta en sus títulos segundo y tercero sobre la organización y administración de los archivos, las facultades del responsable de Área Coordinadora de Archivos y de los responsables de los archivos, incluyendo el histórico.

${ }^{5}$ Para la LFTAIPG.

${ }^{6}$ LFA, Artículo 6, fracc. v.

${ }^{7}$ Alday García, Introducción a la operación, p. 21.

${ }^{8}$ LFA, Artículo 6, fracc. Ix: "Contribuir a la promoción de una cultura de valoración de los archivos y su reconocimiento como eje de la actividad gubernamental". 
de Archivos han difundido las guías y manuales de operatividad en los acervos documentales de las dependencias, con la finalidad de homogeneizar y estandarizar los documentos por medio de técnicas y prácticas (internacionales) para el acceso y control de los archivos en la transparencia de acciones de gobierno, la rendición de cuentas y el acceso a la información, ${ }^{9}$ así como el manejo y uso de la tecnología para el control documental a partir de sistemas electrónicos "para garantizar su confiabilidad y autenticidad en la actualidad y su preservación íntegra en el futuro". ${ }^{10}$

\section{Archivos universitarios y de las instituciones de educación superior}

Las instituciones de educación superior como creadoras y reproductoras de cultura están obligadas a velar, rescatar, preservar, conservar y difundir su patrimonio cultural depositado en los acervos documentales que, a su vez, constituyen el patrimonio nacional. ${ }^{11}$

Las instituciones de educación superior planean y toman decisiones mediante gestiones que requieren de la elaboración de documentos, lo que demanda tiempos y esfuerzos para la adecuada organización y, por ende, dar mantenimiento constante a un archivo universitario que debe ser orgánico, funcional, normativo, fiscal, etcétera. ${ }^{12}$

Los archivos "constituyen parte de la esencia de las instituciones de educación superior, en tanto son el motor que alienta su acción administrativa y la memoria colectiva que refleja su desarrollo diverso a lo largo del tiempo; abarcan la estructura orgánica administrativa y funcional a partir de todas y cada una de las entidades que generan

\footnotetext{
${ }^{9}$ Los servidores públicos están obligados a garantizar la integridad y conservación de los expedientes y documentos, facilitar y controlar su uso y destino final, así como permitir la adecuada conformación de la memoria institucional de las dependencias y entidades de la Administración Pública Federal, "Lineamientos generales...", 2004.

${ }^{10}$ Barnard Amozorrutia, Guía para la organización, p. 8.

${ }^{11}$ Villanueva Bazán, Manual de procedimientos, pp. 5, 7.

${ }^{12}$ Villanueva Bazán, Manual de procedimientos, pp. 5, 6.
} 
documentos en diversas etapas cronológicas". ${ }^{13}$ Son parte toral de la identidad institucional. ${ }^{14}$

Es muy importante que las instituciones de educación superior fomenten la cultura de preservar y conservar el archivo histórico como una buena práctica en pro de la administración pública "favoreciendo la investigación y resguardo de la memoria institucional de México", ${ }^{15}$ cuya contribución a la sociedad es concientizar la importancia del resguardo de los acervos documentales, respetando su procedencia y su orden original "a fin de que se entiendan como verdaderos conjuntos orgánicos y no como simples depósitos de documentación sin orden ni concierto". ${ }^{16}$

Los objetivos que guían a la conservación, catalogación y difusión de los archivos universitarios deben estar orientados a: 1) conservar la memoria histórica de las instituciones universitarias mediante el resguardo del patrimonio documental, y 2) contribuir a la conservación de la memoria nacional con el resguardo de fondos y colecciones particulares cuya temática y contenido sean de interés para el patrimonio documental de la Nación.

\section{Normatividad para el desempeño archivístico en el Ginvestav}

En 1961 se creó el Cinvestav del Instituto Politécnico Nacional (IPN) ${ }^{18}$ con personalidad jurídica y patrimonios propios,

${ }^{13}$ Villanueva Bazán, Manual de procedimientos, pp. 5, 6.

${ }^{14}$ La Red Nacional de Archivos de Instituciones de Educación Superior (RENAIES 2000) que como asociación civil (2009) ha tenido a bien constituirse para conformar una conciencia y una cultura archivísticas desde instituciones educativas y para la sociedad en general; así como contribuir en la normalización de las tareas archivísticas. Entre sus aciertos académicos está el de organizar las Jornadas archivísticas (Xv hasta 2015) para dar a conocer la importancia de la conservación y catalogación de los archivos, así como lo útil de la gestión documental en la administración institucional con perspectivas de fomentar la cultura de los archivos. Villanueva Bazán, Manual de procedimientos, p. 8.

${ }^{15}$ LFA, Artículo 6, fracc. VI.

${ }^{16}$ Villanueva Bazán, Manual de procedimientos, p. 7.

${ }_{17}$ Villanueva Bazán, Manual de procedimientos, p. 11.

18 "Decreto de Creación del Cinvestav", Diario Oficial de la Federación, 1982. 
...con el objeto de preparar investigadores, profesores especializados y expertos en diversas disciplinas científicas y técnicas; en un contexto donde el desarrollo científico y tecnológico del país requería de especialistas e investigadores a nivel de posgrado y de expertos cuyas actividades coadyuvaran al desarrollo, incremento y transmisión de cultura. ${ }^{19}$

Hoy día, el Cinvestav cuenta con 37 departamentos de investigación distribuidos en ocho unidades foráneas y dos sedes en la Ciudad de México; entre ellos: Zacatenco, Sede Sur, Unidad Guadalajara (1987), Langebio, Irapuato (2005), Mérida (1980), Monterrey (2005), Querétaro (1996), Saltillo (1981), Laboratorio de Tlaxcala (1983), Estación Marina Telchac (2006) y Laboratorio de Tecnología de Información (LTI) Unidad Tamaulipas (2006).

El trabajo de organización, descripción y clasificación de los archivos subyace en la legislación y normatividad que rige a la APF. Cabe mencionar que para un buen desempeño archivístico es importante que los funcionarios públicos del Cinvestav conozcan que el ejercicio indebido del servicio es sancionado por el código penal para el Distrito Federal en materia de fuero común y para toda la República en materia del fuero federal, tal como lo advierte su Artículo 214, fracción IV, que dice que debe resguardarse y conservarse "la información o documentación que se encuentre bajo su custodia o a la cual tenga acceso, o de la que tenga conocimiento en virtud de su empleo, cargo o comisión". ${ }^{20}$ Este precepto es sabido, sin embargo, se pasa por alto en virtud del relajamiento al que conllevan las actividades cotidianas de la institución.

Bajo este mismo tenor la Ley Federal de Responsabilidades Administrativas de los Servidores Públicos prescribe, en su Artículo 8, fracción v, que todo servidor público tendrá como obligaciones: "Custodiar y cuidar la documentación e información que por razón de su empleo,

19 "Decreto de Creación del Cinvestav", Diario Oficial de la Federación, 1982.

20 "Código penal para el Distrito Federal”, Artículo 214, fracc. IV. 
cargo o comisión, tenga bajo su responsabilidad e impedir o evitar su uso, sustracción, destrucción, ocultamiento o inutilización indebidos".

Como parte de la cultura archivística, la LFTAIPG instituye que "Los titulares de las dependencias y entidades [...] deberán asegurar el adecuado funcionamiento de los archivos. Asimismo, deberán elaborar y poner a disposición del público una guía simple de sus sistemas de clasificación y catalogación, así como de la organización del archivo". ${ }^{21}$

La importancia de acatar esta disposición por parte del Cinvestav debe ser primordial, como parte de su funcionamiento institucional; la falta de organización y ordenamiento de sus archivos, particularmente en atención a los de trámite, le ponen en desventaja ante las nuevas y modernas técnicas de acceso a la información, la rendición de cuentas y la transparencia en la gestión.

Desafortunadamente, los conceptos de archivo, organización, catalogación, entre otros, no son entendidos desde la cultura archivística; su quehacer aún se percibe como la práctica de ordenar en gavetas y carpetas la documentación. Es por ello que la labor de capacitación $y$, por supuesto, de concientización sobre el tema debe hacerse desde la normatividad correspondiente.

Aunque en las instalaciones del Cinvestav se cuenta ya con un espacio destinado para su archivo de concentración, las labores de organización y clasificación, así como de depuración y catalogación, entre otras, resultan ser tediosas e interminables; dado que este acervo quedó en el abandono y en el desinterés de sus encargados por muchas décadas. Así mismo, la falta de personal especializado hace que esta tarea sea vista como una actividad sin gran relevancia en comparación con las aportaciones científicas y tecnológicas que genera el centro.

Hoy día, a más de una década de desempeño archivístico, el Cinvestav cuenta con un pequeño equipo de trabajo, cuyos integrantes se preocupan por el resguardo y conservación de los documentos y, por ende, de la información institucional. El trabajo de organización del archivo de concentración, a cargo del archivónomo Omar Pérez Durán, ha tenido excelentes resultados para emprender las propuestas

${ }^{21}$ LFTAipg, Artículo 29, fracc. VI. 
de organización y clasificación del acervo; acatando, por supuesto, las disposiciones que determina el marco normativo en materia de archivos para la creación de un catálogo documental.

Tal como lo menciona Pérez Durán, la preservación del archivo de concentración toma importancia desde el momento mismo de reconocer la existencia de un acervo documental; organizándolo y catalogándolo para su buen funcionamiento. Aún falta mucho por hacer. El objetivo es tener y mantener un archivo de concentración que cumpla con la normatividad correspondiente; para ello es necesario fomentar la cultura archivística. ${ }^{22}$

La labor no es nada fácil, al contrario es tediosa, sin embargo, la empresa es prometedora; el interés y el entusiasmo por alcanzar una cultura archivística encausada por la vía de la normatividad y las buenas prácticas hacen que se construyan propuestas encaminadas a la adecuada administración de la información y organización de los archivos del Cinvestav.

En los Lineamientos Generales para la Organización y Conservación de los Archivos de las Dependencias y Entidades de la Administración Pública Federal (2004) se determina que en cada unidad administrativa existirá un archivo de trámite y sus responsables tendrán como funciones: integrar los expedientes de archivos, conservar la documentación que se encuentra activa y aquella que ha sido clasificada como reservada o confidencial conforme al Catálogo de Disposición Documental, coadyuvar con el área coordinadora de archivos, en su caso, con el archivo de concentración, en la elaboración del Cuadro General de Clasificación, el Catálogo de Disposición Documental y el inventario general, valorar y seleccionar los documentos y expedientes de las series documentales, con el objeto de realizar las transferencias primarias al archivo de concentración, conforme al Catálogo de Disposición Documental. ${ }^{23}$

El área coordinadora de archivos será la encargada de elaborar y aplicar las normas, criterios y lineamientos archivísticos determinados. ${ }^{24}$ Mientras que el responsable deberá:

22 Omar Pérez Durán, encargado del archivo de concentración, Cinvestav, 2015.

23 "Lineamientos Generales...", décimo, fraccs. I-IV.

${ }^{24}$ LFA, 2012, Artículo 10. 
Elaborar, en coordinación con los responsables de los Archivos de Trámite, de Concentración y, en su caso, Histórico, el Cuadro General de Clasificación Archivística, el Catálogo de Disposición Documental, el inventario general, así como los demás instrumentos descriptivos y de control archivístico. ${ }^{25}$

De igual manera, los funcionarios vinculados con el quehacer archivístico del centro y sus unidades administrativas deberán atender lo que ordena la LFTAIPG, en cuanto a responsabilizarse de la protección de datos personales de conformidad con los lineamientos que al respecto se establezcan. ${ }^{26}$

No obstante, el trabajo archivístico del Cinvestav será supervisado por un comité de información que asegurará la eficiencia en la gestión de las solicitudes de acceso a la información, confirmar, modificar o revocar la clasificación de la información hecha por los titulares de las unidades administrativas de la dependencia o entidad; realizar, por medio de la unidad de enlace, las gestiones para establecer y supervisar la aplicación de los criterios de clasificación y conservación de los documentos administrativos específicos para la dependencia o entidad, entre otras, más actividades encaminadas a la buena organización y funcionamiento de los archivos. ${ }^{27}$

Así mismo, la unidad de enlace será el vínculo entre el Cinvestav y quien solicita la información. Es la que debe realizar todas las gestiones necesarias a fin de facilitar el acceso a la información. ${ }^{28}$ Los responsables del área deben tener conocimiento y experiencia en archivística, serán nombrados por el titular de la dependencia o entidad. ${ }^{29}$

En el Cinvestav hace falta la iniciativa sobre la creación de un archivo histórico, que si bien, se ha pensado en su existencia, hoy día no existe planeación alguna ni proyecto oficial a largo plazo para su fundación.

\footnotetext{
${ }^{25}$ LFA, 2012, Artículos 10-12, fracc. III.

${ }^{26}$ LFTAIPG, Artículo 20, fraccs. I-IV.

${ }^{27}$ LFTAIPG, Artículo 29, fraccs. II-VI.

${ }^{28}$ LFTAIPG, Artículo 41.

${ }^{29}$ Tercero y sexto de los "Lineamientos Generales...".
} 
No obstante, en los acervos documentales del Cinvestav existen las evidencias documentales que dan cuenta de su trayectoria histórica, acervo que requiere del espacio adecuado para exhibir públicamente sus aportaciones a la ciencia y a la tecnología; sin olvidar lo importante que fue en su momento la creación de sus unidades foráneas. Con la creación de un archivo histórico que resguarde los bienes patrimoniales que ha generado el centro a lo largo de sus 55 años de existencia, sin duda, será un aporte significativo a la investigación científica.

A más de medio siglo de historia institucional, el Cinvestav ha generado un patrimonio propio, no sólo en recursos humanos y financieros, sino un bagaje cultural emanado de sus investigaciones que han impactado en la ciencia y en el uso de la tecnología para el desarrollo social y científico del país, como las colecciones de investigaciones científicas tanto en las ciencias duras como en las humanidades.

Este patrimonio propio se convierte en histórico en tanto que conserva una memoria documental que torna ser el conjunto de bienes científicos, técnicos, bibliográficos, documentales y artísticos; materiales como inmateriales acumulados a lo largo del tiempo, toda vez que en ellos se reúnen los saberes, valores y símbolos que dan identidad, cohesión, reconocimiento, sentido y perspectiva histórica. Este patrimonio documental es lo que da identidad al Cinvestav, merecedor de ser atendido por la normatividad archivística adecuada. $^{30}$

\section{Prácticas de archivística en los archivos de la Coor- dinación Académica del DIE-GinvesTaV}

El Departamento de Investigaciones Educativas (DIE) fue creado, en 1971, como dependencia del Cinvestav, con el interés nacional por la investigación educativa. Su labor se inició con la elaboración de los nuevos textos de enseñanza a nivel primaria (1971-1980). Sus investigaciones se vinculan con otras instituciones oficiales (SEP, Conacyt

\footnotetext{
${ }^{30}$ Maruri Carrillo, "Archivos administrativos".
} 
y algunas más) y con aquellas financiadas por agencias no gubernamentales (OREALC, UNESco, CONAFE, Ford, entre otras)..$^{31}$

En el DIE se encuentran varios acervos que resguardan información activa, semiactiva e inactiva, hay documentación de trámite y de concentración; así como un acervo bibliográfico y fotográfico, resguardado en la biblioteca, que puede dar inicio a lo que sería el archivo histórico. ${ }^{32}$

El Archivo de la Coordinación Académica (ACA) del DIE-Cinvestav concentra información de los Programas de Posgrado en Ciencias en la Especialidad en Investigaciones Educativas, susceptible de ser organizada y clasificada acatando la normatividad archivística actual. ${ }^{33}$ Los expedientes contienen datos confidenciales de cada uno de los estudiantes y egresados, los cuales deben ser manejados de acuerdo con la normatividad que marcan los Lineamientos de Protección de Datos Personales $^{34}$ y por lo que dicta la LFTAIPG. ${ }^{35}$

En lo que se conoce como "archivo muerto"36 existe documentación con respecto a la trayectoria académica de sus investigadores y egresados, misma que podría ser reorganizada en archivos de concentración e histórico.

${ }^{31}$ Departamento de Investigaciones Educativas (en adelante DIE), Cinvestav. Disponible en: http://www.die.cinvestav.mx/Antecedentes.aspx. [2015].

${ }^{32}$ Maruri Carrillo, "Proyecto. Organización y catalogación".

${ }^{33}$ Maruri Carrillo, "Proyecto. Organización y catalogación".

${ }^{34} \mathrm{El}$ acceso restringido a la información reservada y confidencial requiere asegurar su conservación y custodia, por lo cual los archivos se convierten en el instrumento fundamental para evitar que se usen, oculten, destruyan, divulguen o alteren indebidamente los expedientes y documentos ("Lineamientos Generales...", 2004).

${ }^{35}$ En sus Artículos 13 y 18 se reglamenta que: "la información reservada podrá clasificarse como aquélla cuya difusión pueda comprometer la seguridad nacional, la seguridad pública o la defensa nacional; y como información confidencial se considerará: I. La entregada con tal carácter por los particulares a los sujetos obligados... y II. Los datos personales que requieran el consentimiento de los individuos para su difusión, distribución o comercialización..."

${ }^{36}$ Aunque este término ya está en desuso y que dentro de la cultura archivística no tiene sentido de ser, la costumbre está muy arraigada en el DIE-Cinvestav para referirse a lo que corresponde a un archivo de concentración. 
La información activa está concentrada en carpetas clasificadas con temas relacionados con la vida académica de los estudiantes inscritos en los programas y planes de estudios en maestría y doctorado que ofrece el Departamento: solicitudes, documentos de aceptación, trámites, actas de exámenes, actas de ingreso, calificaciones, formatos, manuales, etcétera. El programa de maestría está ordenado por generaciones y el de doctorado por orden alfabético de los doctorantes. ${ }^{37}$ Este archivo de trámite tiene un carácter cotidiano ya que día a día se manipula la información y el ciclo de vida de la documentación se encuentra en sus primeros valores archivísticos.

Asimismo, hay una sección documental en la Coordinación Académica que contiene información semiactiva, en los archiveros se localizan expedientes de alumnos egresados del posgrado del DIE, de generaciones anteriores a cinco años. En este caso se trata de un archivo de concentración que necesariamente debe acatar los lineamientos de los manuales de archivística y los marcos jurídicos correspondientes.

Es importante mencionar que entre estos dos acervos se perciben documentos que pueden formar parte del archivo histórico del DIE, dadas sus características: testimonial, informativa y evidencial. El DIE alberga un archivo que contiene información histórica desde los orígenes del Departamento, así como la trayectoria académica de sus investigadores. ${ }^{38}$

Simultáneamente, el ACA-DIE lo conforma una base de datos electrónica denominada Sistema Integral de Información Académica (SIIA) donde se resguarda la vida académica de los estudiantes DIE, existe información confidencial de profesores y alumnos, así como reportes, informes y catálogos del posgrado.

Hoy día, la información de la Coordinación Académica del DIECinvestav se maneja por medio de un google drive como instrumento de

\footnotetext{
${ }^{37}$ Información proporcionada por Rosa María Martínez Frías, apoyo secretarial, quien ha sido la encargada de manejar la información de la Coordinación Académica desde hace más de veinte años.

${ }^{38}$ Información proporcionada por Socorro Miranda, encargada de Biblioteca-DIE 2015.
} 
concentración de la información, con la finalidad de optimizar el manejo de la información. ${ }^{39}$ Es así como se tiene un archivo digital; independiente mente de las bases de datos concentradas en carpetas electrónicas de uso cotidiano en programas de Word, Excel y PDF. Dicha práctica cumple con "la utilización de tecnologías de la información para mejora de la administración de los archivos por los sujetos obligados". ${ }^{40}$

El ACA-DIE es un fondo de la APF, por lo que sus funciones deben apegarse a los criterios de organización y conservación emitidas por la normatividad en materia de archivos e información pública actual. En este caso "La Coordinación Académica es la responsable de ejecutar y organizar el trabajo de los programas de posgrado; coordina las actividades académico-administrativas y de apoyo para el desarrollo de la maestría y el doctorado". Entre las funciones del coordinador académico está la de "Proporcionar y coordinar la producción de la información académica solicitada por instancias externas oficiales, en colaboración con los profesores del Departamento". ${ }^{41}$

Particularmente, el ACA-DIE atiende necesidades de un colectivo en materia educativa y cultural por medio de dos archivos administrativamente reconocibles, que son de trámite y de concentración dentro de las operaciones cotidianas. Para la organización de estos archivos, como parte de la buena práctica, se requiere de planear, dirigir y controlar los mecanismos y estrategias de organización, clasificación y catalogación de los múltiples y variados documentos oficiales. Para con ello investigar, prever, planear, organizar, integrar y dirigir la catalogación que servirá para la elaboración de los instrumentos de consulta pública. ${ }^{42}$

39 Información proporcionada por la maestra Aleida García Aguirre. Apoyo técnico y administrativo en la Coordinación Académica del DIE (2014-2015).

${ }^{40}$ LFA, Artículo 6, fracc. VII.

${ }^{41}$ El coordinador académico es nombrado por la Dirección General, a propuesta del Colegio de Profesores. Es la Jefatura quien notifica su nombramiento a la Subdirección de Posgrado del Cinvestav. Reglamento interno del programa del doctorado en Ciencias en la Especialidad de Investigaciones Educativas. 2014, México, Cinvestav-DIE (en adelante Reglamento Interno...).

${ }^{42}$ Alday García, Introducción a la operación, p. 21. 
La operatividad y el buen funcionamiento se determinan con la adecuada administración documental. Para ello es fundamental reconocer la etapa de vida por la que atraviesa cada documento. A cada fase corresponde un tratamiento especializado y una adecuada conservación en un archivo específico. La primera es la fase activa o de vigencia administrativa, en ésta el documento adquiere diferentes valores:

- Valor administrativo: como la condición de los documentos producidos o recibidos por una institución para realizar sus funciones o actividades comunes. ${ }^{43}$

- Valor jurídico o legal: condición de los documentos que permite certificar derechos u obligaciones de la administración pública o de los ciudadanos.

- Valor fiscal o contable: atributo de los documentos para comprobar el origen, distribución y uso de los recursos financieros de una institución.

La fase semiactiva es cuando el documento conserva sus valores primarios (administrativo, jurídico o fiscal). Su uso es ocasional, por ello es necesario conservarlo durante un plazo precautorio; su conservación debe ser en un archivo de concentración.

Finalmente, en la fase histórica el documento ha perdido sus valores primarios para la institución, pero conserva valores secundarios:

- Valor evidencial: utilidad permanente de los documentos en virtud de su relación con derechos imprescriptibles de las personas físicas o morales.

- Valor testimonial: utilidad permanente de los documentos por reflejar la evolución del organismo que los creó.

- Valor informativo: utilidad permanente de que los documentos aportan datos únicos y sustanciales para la investigación y el estudio en cualquier campo del saber.

${ }^{43}$ Alday García, Introducción a la operación, p. 25. 
En esta etapa, su uso ya no es institucional sino social. Su conservación debe ser permanente en el archivo histórico, donde recibirá una clasificación y un tratamiento especializado. Al final de este proceso vital de los documentos se llega a la depuración (baja documental). Los documentos que al finalizar su fase semiactiva y perder los valores primarios no presentan valores secundarios y pueden ser eliminados de acuerdo con las normas que marque la propia institución al respecto, previo análisis y valoración de los mismos. ${ }^{44}$

\section{Archivo de trámite (manejo de la documentación activa)}

La LFA ordena que "en cada unidad administrativa de los sujetos obligados existirá un archivo de trámite, en el que se conservarán los documentos de uso cotidiano necesarios para el ejercicio de las atribuciones de las unidades administrativas". ${ }^{45}$

Los responsables de los archivos de trámite serán nombrados por el titular de cada unidad administrativa, quien deberá ser debidamente capacitado para cumplir con sus funciones, entre ellas:

Conservar la documentación que se encuentre activa y aquella que ha sido clasificada como reservada de acuerdo con la LFTAIPG, y coadyuvar con el área coordinadora de archivos en la elaboración del Cuadro General de Clasificación Archivística, el Catálogo de Disposición Documental y el Inventario general. ${ }^{46}$

El archivo de trámite en el ACA-DIE debe ser organizado desde el momento de la recepción en consideración a los principios de procedencia y de origen. Las políticas que legitiman de manera legal, los criterios

\footnotetext{
${ }^{44}$ Alday García, Introducción a la operación, p. 26.

${ }^{45}$ LFA, 2012, Artículo 14.

${ }^{46}$ LFA, 2012, Artículo 10; fraccs. II-III.
} 
y lineamientos de un archivo de acuerdo con su carácter seriado (proceso natural de una actividad o función, son únicos, tienen autoridad, son estáticos y se interrelacionan entre sí) son: ${ }^{47}$

- Recepción y despacho correspondencia. Acto jurídico y administrativo que compromete a la dependencia como tal para la realización expedita y eficiente de un trámite institucional. ${ }^{48}$

- Seguimiento y control de documentos en trámite. Aspecto medular tanto para el correcto y oportuno desarrollo de la gestión administrativa, como para la adecuada integración y preservación de los recursos informativos de las instituciones. Aquí destaca el vínculo entre la labor administrativa y el trabajo documental, lo que hace que su cumplimiento efectivo requiera de la participación de administradores y archivistas. $^{49}$

- Despacho de correspondencia. Garantiza que los documentos generados por las entidades administrativas de la dependencia sean recibidos oportuna y completamente por sus destinatarios. ${ }^{50}$

- Organización y control de expedientes. Mantener el seguimiento y control de los documentos sujetos a trámite hasta su integración final al archivo. Conservar sistemáticamente organizados los documentos gestionados por la dependencia y así garantizar su fácil localización y consulta. ${ }^{51}$

Cada uno de estos lineamientos responde a objetivos específicos de acuerdo con el uso y manejo de la documentación. Es importante que, los expedientes antes de su transferencia al archivo de concentración deban ser expurgados.

${ }^{47}$ Alday García, Introducción a la operación, p. 29; Barnard Amozorrutia, Guía para la organización, pp. 19, 20.

${ }^{48}$ Alday García, Introducción a la operación, p. 29.

${ }^{49}$ Alday García, Introducción a la operación, p. 31.

${ }^{50}$ Alday García, Introducción a la operación, p. 34

${ }^{51}$ Alday García, Introducción a la operación, p. 35. 
Hoy día, es necesario acatar estas disposiciones en el archivo de trámite de la Coordinación Académica del DIE-Cinvestav dado que el conocimiento del proceso de organización aún se desconoce para quienes se ven involucrados, de manera directa, con el manejo de documentos activos.

Dicho desempeño debe considerar, en primera instancia, las actividades sustantivas y comunes del Cinvestav identificadas por medio de su Manual General de Organización, así como su organigrama institucional, en virtud de generar un Cuadro de Clasificación Documental del DIE, ${ }^{52}$ Cuadro General de Clasificación Achivística Cinvestav ${ }^{53}$ y los Lineamientos Generales para la administración del Archivo de Trámite, ${ }^{54}$ que permitan ordenar la documentación generada por la Coordinación. En este caso se identificarán las series sustantivas de la Coordinación Académica del DIE, ${ }^{55}$ como planes y programas de estudio de los posgrados, convocatorias, catálogos de posgrado, informes para el Consejo Nacional de Ciencia y Tecnología (Conacyt) y el Programa Nacional de Posgrados de Calidad (PNPC), becas, expedientes académicos, etcétera.

\section{Archivo de concentración (manejo de la documentación semiactiva)}

La Coordinación Académica del DIE-Cinvestav cuenta con un acervo documental. En éste se resguardan los expedientes de alumnos egresados del posgrado. Sin embargo, falta clasificarlo y catalogarlo tal como lo dicta la normatividad correspondiente; para su infortunio, carece del trato y de los instrumentos adecuados para su organización y reconocimiento.

A este espacio se transfieren los documentos del archivo de trámite cuando su consulta por los organismos productores es esporádica,

\footnotetext{
${ }^{52}$ Maruri Carrillo, "Cuadro de clasificación documental".

${ }^{53}$ Maruri Carrillo, "Cuadro General de Clasificación".

${ }^{54}$ Maruri Carrillo, "Lineamientos Generales".

55 "Coordinadores DIE. Cinvestav", disponible en http://www.die.cinvestav.mx/ Coordinadores.aspx [2015].
} 
y ahí permanecerán hasta su eliminación o transferencia al archivo histórico. Este espacio debe adscribirse al área coordinadora de archivos tal como lo estipulan los Lineamientos Generales en su Artículo decimoprimero.

En esta etapa se realizará la transferencia documental en tanto que es el traslado controlado y sistemático de los expedientes semiactivos al archivo de concentración y de los inactivos al archivo histórico (cuando lo haya, en este caso el Cinvestav aún no cuenta con el espacio y las condiciones para albergar a este tipo de archivo). ${ }^{56}$

Durante la instancia de los documentos en este archivo de concentración se acatarán los lineamientos de la disposición documental determinada por una valoración normada y reglamentada por los plazos de conservación, de transferencia y depuración, considerando su conservación precautoria. ${ }^{57}$ Es decir, obedecen a las políticas de vigencia y permanencia en los acervos documentales.

La unidad de archivo de concentración debe informar sobre la depuración, transferencias y bajas o cualquier otro tratamiento de los documentos. Además llevará un registro completo de los expedientes.

En este caso, es necesario elaborar los Lineamientos Generales para la administración del Archivo de Concentración del DIE-Cinvestav, con la finalidad de identificar los periodos de vida para la documentación y clasificar de manera adecuada según fondo, subfondo, sección y series. Propuesta que debe contener el inventario del acervo y la descripción de series y subseries de los documentos, con el objetivo de coadyuvar en la creación del Catálogo de Disposición Documental que por ley debe existir para su óptima organización.

El Catálogo de Disposición Documental se elaborará mediante cuatro etapas: identificación, valoración, regulación y control que permitirán la integración de la información para el adecuado manejo de la documentación en cada una de las fases de su ciclo vital; así como para su disposición y accesibilidad.

\footnotetext{
${ }^{56}$ Alday García, Introducción a la operación, p. 38.
}

${ }^{57}$ Alday García, Introducción a la operación, p. 40. 
Para ello se requiere de la identificación que consiste en la investigación y análisis de las características de los elementos esenciales que constituyen la serie documental, la función, el sujeto productor y el documento de archivo. Así como la valoración que determina los valores primarios y secundarios de la documentación, requerimiento para fijar plazos de acceso, transferencia, conservación o eliminación. ${ }^{58}$

En la regulación se integrará el Catálogo de Disposición Documental en los formatos establecidos, determinando con toda claridad los plazos de conservación y las técnicas de selección. En la última fase de control se valida y aplica el catálogo por parte de los funcionarios autorizados así como de la Coordinación de Archivos y el Comité de Información. ${ }^{59}$

También es importante procesar un Cuadro General de Clasificación Archivística, inventarios documentales donde se registren las bajas y las transferencias documentales, la guía simple y el reglamento interno para el buen manejo de la información y el resguardo de los archivos.

La organización y catalogación de los archivos de la CA-DIE, requieren de dedicación y tiempo completo con personal conocedor y diestro en el tema, dedicando todo su tiempo a la ardua tarea que implica meses de trabajo para inventariar, organizar y catalogar documentos que han sido generados, por lo menos, durante 22 generaciones de posgrado.

Independientemente del tiempo asignado para realizar estas arduas tareas, que requiere desde varios meses hasta más de un año; es necesario, dedicar los espacios y el personal adecuado que garanticen el proceso de catalogación y la continuidad de la clasificación y conservación de los archivos.

\section{Archivo histórico (manejo de la documentación inactiva)}

Esta es la tercera etapa de los documentos dentro del ciclo vital, al que se han de trasladar desde el archivo de concentración para su conservación permanente. Sus fondos están constituidos por series documentales

\footnotetext{
${ }^{58}$ Instructivo para la elaboración, pp. 10-11.

${ }^{59}$ Instructivo para la elaboración, p. 13.
} 
transferidas por el o los distintos archivos de concentración de la administración. También puede conservar documentos recibidos por donación, depósito o adquisición. ${ }^{60}$

De acuerdo con la ley en materia de archivos, el archivo histórico estará adscrito al área coordinadora de archivos y se constituirá como fuente de acceso público, encargado de divulgar la memoria documental institucional, estimular el uso y el aprovechamiento social de la documentación así como difundir su acervo e instrumentos de consulta. ${ }^{61}$

En cada una de las etapas vitales de los documentos se mantienen su principio de procedencia y orden de origen. Esto según la entidad que lo promovió. Su orden original se determina por el lugar que ocupa en el grupo documental: "Todo documento tiene un lugar determinado en el grupo documental, y este orden hay que respetarlo o restituirlo si se ha modificado. Sin olvidar la estructura de los documentos que permite el control y la recuperación de cada unidad del acervo". ${ }^{62}$

La clasificación depende de la estructura orgánica de la dependencia de la que procede, es consecuencia del análisis de los principios de procedencia y de origen que conlleva a formar el esquema de organización del archivo; "fondo", "sección" y "serie" que constituyen el principio de diferenciación, estratificación y jerarquía de los diversos grupos documentales que conforman el acervo. Así, los documentos se agrupan en: fondo, subfondo o sección, serie, subserie, expediente, unidad documental. ${ }^{63}$

Para el caso del ACA-DIE, la clasificación debe considerar las unidades documentales, que pueden ser compuestas (expediente) o simples (documento) de acuerdo con su composición interna, aunque el expediente es la unidad básica de la serie, por lo que es importante saber distinguir expediente, documento, registro, dossier; singulares o simples. ${ }^{64}$

\footnotetext{
${ }^{60}$ Alday García, Introducción a la operación, p. 48.

${ }^{61}$ LFA, 2012, Artículo 17.

${ }^{62}$ Alday García, Introducción a la operación, pp. 50, 51.

${ }^{63}$ Alday García, Introducción a la operación, pp. 50, 51.

${ }^{64}$ Alday García, Introducción a la operación, p. 53.
} 
Este archivo también requiere de los Lineamientos Generales para la creación y organización del archivo histórico del Cinvestav ${ }^{65}$ donde se argumenta la existencia de este acervo como un bien patrimonial del centro, desde el momento de su creación, así como de las diversas aportaciones que sus estudiosos han realizado en las investigaciones educativas en los diferentes contextos sociales, políticos y culturales que México, como país pluricultural, ha vivido a lo largo de su proceso histórico.

Un aporte significativo que ha hecho el DIE a la historia social de México, se enmarca en el ámbito educativo del último tercio del siglo xx, con la colaboración de investigadores de la talla de Elsie Rockwell y Antonia Candela, destacadas investigadoras que participaron en la elaboración de los Libros de Texto Gratuito en la década de los setentas; libros que fueron el cimiento de la educación básica de varias generaciones.

En el momento que el DIE-Cinvestav comience con el cambio en torno a la adecuada administración documental siguiendo una cultura archivística se conocerán, realmente, los potenciales y problemáticas del proceso de organización y catalogación de sus archivos. La proyección de un archivo histórico develará el potencial social y cultural que la Institución ha tenido a lo largo de varias décadas de investigación y docencia cuyos resultados son el bien patrimonial que heredará a generaciones futuras.

\section{Conclusiones}

Los archivos en México están protegidos por un amplio marco jurídico que regula los lineamientos para la conservación de los archivos como patrimonio institucional, comenzando con la LFA. En las medidas implementadas se observa el trabajo de los archivistas que por años han sabido cavilar una cultura para la organización y catalogación de los archivos, así como los valores y reconocimientos que deben tener estos repositorios para la administración pública.

${ }^{65}$ Maruri Carrillo, "Lineamientos generales...". 
De acuerdo con Alday García, la organización de un archivo consiste en el conjunto de operaciones intelectuales y mecánicas por las que los diferentes grupos documentales se relacionan en forma jerárquica con criterios orgánicos o funcionales, para revelar su contenido y para tener el control de cada pieza y del conjunto de documentos. Para que finalmente se obtenga el registro y descripción de los documentos y así elaborar guías, inventarios, catálogos e índices. ${ }^{66}$

La práctica archivística es una labor sumamente especializada, denotada por medio del proceso que implica desde la selección, descripción y clasificación de los documentos para determinar su procedencia, su estructura y la información contenida, hasta la catalogación de los documentos para la administración pública determinada por la normatividad en la materia.

La percepción de la cultura archivística en el DIE-Cinvestav debe ser valorada desde la responsabilidad que adquiere como dependencia gubernamental, acatando las disposiciones de la administración pública, priorizando, sobre todo, el acceso a la información, rendición de cuentas y la transparencia en la gestión.

Sin olvidar que en la documentación se resguarda el patrimonio institucional ${ }^{67}$ conformado por muebles e inmuebles, documentos y expedientes, manuscritos, ediciones, libros, documentos, publicaciones periódicas, folletos, piezas etnológicas, colecciones científicas o técnicas, archivos, fonograbaciones, películas, archivos fotográficos, cintas magnetofónicas y cualquier otro objeto que contenga imágenes y sonidos, las piezas artísticas o históricas de los museos. Materiales que le dan identidad nacional y que por ley ${ }^{68}$ están protegidos.

En este caso, la cultura archivística es entendida como el conjunto de acciones e ideologías encaminadas a la preservación, conservación y valoración documental en beneficio de la investigación documental, con base en la correcta administración de la cual devienen las buenas

\footnotetext{
${ }^{66}$ Alday García, Introducción a la operación, pp. 54-62; Barnard Amozorrutia, Guía para la organización, p. 29.

${ }^{67}$ Maruri Carrillo, "Archivos administrativos".

68 "Ley General de Bienes Nacionales" (LGBN), Artículo 2º fracc. I.
} 
prácticas de salvaguardia en pro de la protección patrimonial de entidades y dependencias gubernamentales.

Por ello es necesario concientizar en materia de prácticas archivísticas a los funcionarios que estén estrechamente relacionados con la noble labor de los archivos, en tanto que son la evidencia histórica del desarrollo institucional y nacional del país. Tal pareciera que los planteamientos, las disposiciones y los lineamientos jurídicos e institucionales son expedidos sin ninguna arbitrariedad. Sin embargo, el proceso de organización y catalogación de los archivos de las entidades y dependencias se ve obstaculizado por la falta de cultura archivística de funcionarios que omiten el valor de los documentos, y por ende, no perciben la trascendencia de los acervos documentales como patrimonio institucional; más aún, desconocen el marco jurídico que protege dicho patrimonio. 


\section{Fuentes}

\section{Bibliografía}

Alday García, Araceli J., Introducción a la operación de archivos en dependencias y entidades del Poder Ejecutivo Federal, México, Archivo General de la Nación (en adelante AGN), Sistema Nacional de Archivos, Comité Técnico Consultivo de Unidades de Correspondencia y Archivo, s. f.

Barnard Amozorrutia, Alicia, Guía para la organización y control del expediente del archivo, México, Secretaría de Gobernación-AGN, 2002.

Instructivo para la elaboración del Catálogo de Disposición Documental, México, AGN-Dirección del Sistema Nacional de Archivos, 2012.

Maruri Carrillo, María Elena, "Organización y catalogación del Archivo de la Coordinación Académica del Departamento de Investigaciones Educativas del Cinvestav", Proyecto DIE-Cinvestav, 2015.

, "Cuadro de Clasificación Documental", Documento 1, DIE-Cinvestav, 2015.

, "Cuadro General de Clasificación Archivística Cinvestav", Documento 2, Cinvestav, 2015.

"Lineamientos generales para la administración del Archivo de Trámite Cinvestav", Documento 3, Cinvestav, 2015.

, "Lineamientos generales para la creación y organización del Archivo Histórico del Cinvestav", Documento 4, Cinvestav, 2015.

, "Archivos administrativos: Memoria histórica y patrimonio documental Cinvestav", Documento 5, Cinvestav, 2015. 
Maruri Carrillo, María Elena et al., "Guía documental del Archivo Histórico de San Antonio la Isla, Estado de México. Agricultura y ganadería (1827-1968), Educación pública (1841-1976), Iglesia (Asuntos eclesiásticos 1743-1977), Recursos naturales y forestales (1851-1984), Salubridad y asistencia (1868-1900), Tierras (16031984)", a través del Plan de Desarrollo Municipal de San Antonio la Isla, Inédito, 2012.

Villanueva Bazán, Gustavo et al., Manual de procedimientos técnicos para archivos históricos de universidades e instituciones de educación superior, México, Benemérita Universidad Autónoma de Puebla-Universidad Nacional Autónoma de México (Centro de Estudios sobre la Universidad. Archivo Histórico de la UNAM), s. f.

\section{Fuentes de consulta}

"Acuerdo por el que se dispone que el Archivo General de la Nación, será la entidad central y de consulta del Ejecutivo Federal en el manejo de los archivos administrativos e históricos de la Administración Pública Federal”, 1980.

http://dof.gob.mx/nota_detalle.php? codigo $=4856603 \& \mathrm{fe}$ cha $=14 / 07 / 1980$ [2015].

"Decreto de creación del Cinvestav, 1982, Diario Oficial de la Federación", t. CCCLXXIV, núm. 17.

https://www.Cinvestav.mx/Portals/0/SiteDocs/Sec_Conocenos/ Decreto.pdf, [2015].

"Estatuto Orgánico del Archivo General de Nación”, 2012. http://bit.ly/2f0xTMG [2015].

"Ley de Transparencia y Acceso a la Información Pública Gubernamental", última reforma 2014.

http://www.diputados.gob.mx/LeyesBiblio/pdf/244_140714. pdf [2015]. 
"Ley Federal de Archivos", 2012.

http://www.diputados.gob.mx/LeyesBiblio/pdf/LFA.pdf [2015].

"Ley Federal de las Entidades Paraestatales", última reforma, 2014.

http://www.diputados.gob.mx/LeyesBiblio/pdf/110_110814.pdf [2015].

"Ley General de Bienes Nacionales" (2004).

www.diputados.gob.mx/LeyesBiblio/pdf/267_010616.pdf [2016].

"Ley Orgánica de la Administración Pública Federal”, 2015.

http://www.diputados.gob.mx/LeyesBiblio/pdf/153_130515.pdf [2015].

"Lineamientos de Protección de Datos Personales", 2005.

http://inicio.ifai.org.mx/MarcoNormativoDocumentos/lineamientos_protdaper.pdf [2015].

"Lineamientos para La Organización y Conservación de los Archivos de las Dependencias Y Entidades de la Administración Pública Federal", 2004.

http:/ / www.dof.gob.mx/nota_detalle.php?codigo=679839\&fe cha $=20 / 02 / 2004$ [2015].

"Reglamento Interno del Programa de Doctorado en Ciencias en la Especialidad de Investigaciones Educativas", México, Cinvestav-DIE, 2014.

"Reglamento de la Ley Federal de Archivos", 2014. http://bit.ly/loLGQcn [2015].

\section{Referencias electrónicas}

"Departamento de Investigaciones Educativas", Cinvestav. http://www.die.Cinvestav.mx/Antecedentes.aspx [2015].

"Coordinadores DIE-Cinvestav". http://www.die.Cinvestav.mx/Coordinadores.aspx [2015]. 
"Instituto de Acceso a la Información Pública y Protección de Datos Personales del Distrito Federal", Sistema Institucional de Archivos, Comité Técnico Interno de Administración de Documentos. http://www.infodf.org.mx/web/index.php?option=com_content\& task=view\&id=954 [2015].

"Red Nacional de Archivos de Instituciones de Educación Superior A. C." http://www.renaies.org/ [2015]. 